\title{
Removal of dieldrin from aqueous solution by a novel triolein-embedded composite adsorbent
}

\author{
Jia Ru ${ }^{\text {a,b, }, \text {, Huijuan Liu }}{ }^{\text {a }}$, Jiuhui Qu ${ }^{\mathrm{a}, *}$, Aimin Wang ${ }^{\text {a }}$, Ruihua Dai ${ }^{\text {a,b }}$ \\ ${ }^{a}$ State Key Laboratory of Environmental Aquatic Chemistry, Research Center for Eco-Environmental Sciences, \\ Chinese Academy of Sciences, P.O. Box 2871, Beijing 100085, China \\ ${ }^{\mathrm{b}}$ Graduate School of Chinese Academy of Sciences, Beijing 100039, China
}

Received 23 March 2006; received in revised form 22 June 2006; accepted 23 June 2006

Available online 28 June 2006

\begin{abstract}
In this study, a novel triolein-embedded activated carbon composite adsorbent (CA-T) was prepared and applied for the adsorption and removal of dieldrin from aqueous systems. Experiments were carried out to investigate the adsorption behavior of dieldrin on CA-T, including adsorption isotherms, adsorption kinetics, the influence of initial concentration, temperature, shaking speed, $\mathrm{pH}$ and the addition of humic acid (HA) on adsorption. The adsorption isotherms accorded with Freundlich equation. Three kinetics models, including pseudo-first-order, pseudo-secondorder and intraparticle diffusion models, were used to fit the experimental data. By comparing the correlation coefficients, it was found that both pseudo-second-order and intraparticle diffusion models were used to well describe the adsorption of dieldrin on CA-T. The addition of HA had little effect on dieldrin adsorption by CA-T. Results indicated that CA-T appeared to be a promising adsorbent for removing lipophilic dieldrin in trace amount, which was advantageous over pure granular activated carbon (GAC). The adsorption rate increased with increasing shaking speed, initial concentration and temperature, and remained almost unchanged in the $\mathrm{pH}$ range of $4-8$. Thermodynamic calculations indicated that the adsorption reaction was spontaneous with a high affinity and the adsorption was an endothermic reaction.
\end{abstract}

(C) 2006 Elsevier B.V. All rights reserved.

Keywords: Activated carbon; Adsorption; Persistent organic pollutants (POPs); Triolein

\section{Introduction}

Persistent organic pollutants (POPs), such as organochlorines, have been of great concern due to their characteristics of toxicity, persistency and bioaccumulation, despite bans on production and usage [1-3]. Many of these compounds are considered to act as environmental hormones, which disrupt reproductive cycles of humans and wildlife [4]. Although methods to remove residual POPs from the environment have been taking on increasing attention internationally in recent years [5], most hazardous vestigial POPs with low water solubility are especially difficult to be eliminated from water. Activated carbon, with a high degree of porosity and an extensive surface area, has been widely used as an effective adsorbent for sev-

\footnotetext{
* Corresponding author. Tel.: +86 1062849151 ; fax: +86 1062923558.

E-mail addresses: rujia_china@ hotmail.com (J. Ru), hjliu@ rcees.ac.cn (H.Liu), jhqu@ rcees.ac.cn(J.Qu), wangaimin199771@ sina.com.cn(A. Wang), dairuihualg@sohu.com (R. Dai).

1 Tel. +8610 62849137; fax: +86 1062849160 .
}

eral organic compounds of concern in water and wastewater treatment [6-8]. However, with poor selectivity to organic pollutants and saturation-prone property, activated carbon needs to be regenerated frequently during the adsorption process, and it cannot remove hydrophobic POPs in trace or ultratrace amounts near the environmental level from water satisfactorily. Consequently, it is attractive to develop novel adsorbents to remove organic micropollutants from water efficiently.

Based on the bioaccumulative property of POPs in fatty tissue [9], a novel triolein-embedded activated carbon composite adsorbent (CA-T) was developed in this research. The adsorbent is mainly composed of the supporting activated carbon and the surrounding triolein-embedded cellulose acetate membrane. Several researchers have found that triolein has a high accumulating capacity $\left(10^{5}-10^{7}\right)$ for trace lipophilic chemicals [10,11]. Moreover, triolein is naturally found in fatty tissue of animals, and so it is inexpensive to purchase and safe to use in adsorption procedures. Cellulose acetate, a particularly useful polymer for preparing hybrid materials, was used to combine triolein with activated carbon. Cellulose acetate can be easily molded 
into different forms, such as membranes, fibers and spheres [12], and its hydrophilicity improves the accessibility of aqueous solutions to the surface of hybrid materials. The molecular size-exclusion limit of cellulose acetate membrane is similar to that of the biomembrane, while triolein constitutes lipid pools that can accumulate hydrophobic organic contaminants. Accordingly, the novel triolein-embedded composite adsorbent was prepared with these pollution-free and environmental-friendly raw materials.

This paper focuses on investigating the adsorption behavior of dieldrin, a model contaminant, on the novel triolein-embedded composite adsorbent, compared to the commercially used granular activated carbon (GAC) and to the composite adsorbent containing no triolein (CA). Batch adsorption experiments were carried out to study the adsorption isotherms and adsorption kinetics. The effects of different factors on the removal rate, such as initial concentration, temperature, shaking speed, $\mathrm{pH}$ and the addition of humic acid were also studied in detail.

\section{Experimental}

\subsection{Materials}

\subsubsection{Adsorbent}

Granular activated carbon ZJ-15 (GAC, Xinhua Acitvated Carbon Co. Ltd., Shanxi, China) was selected in this study, which is widely used in the water treatment plants in China and offers a high purity level. Triolein ( $>99 \%$ purity) was purchased from Sigma Chemical Co. (St. Louis, MO, USA), and cellulose acetate (2.5 degree of acetylation) was obtained from Shanghai Chemical Reagent Co. (Shanghai, China). Materials for the preparation of the composite adsorbent also included acetone (A.R.), 1,4-dioxane (A.R.) and magnesium perchlorate (A.R.), which were all purchased from Beijing Chemical Reagent Co. (Beijing, China). Magnesium perchlorate was ground in a mortar to remove coarse particles before use.

Preparation method had been shown in previous published papers and patents [13,14] and was briefly described here. Dissolving cellulose acetate with acetone and 1,4-dioxane resulted in the formation of a mixed membrane solution, which was used to coat the surface of GAC. Magnesium perchlorate was added as an additive, and certain amount of triolein was also added. Then the mixture was stirred at room temperature for $48 \mathrm{~h}$ to dissolve triolein in membrane solution homogeneously. After that, activated carbon was dipped in the solution for $5 \mathrm{~min}$ and then taken out and put in an aerator for 1 min to make solvent evaporate. The composite adsorbent was immersed in a water coagulation bath $\left(25^{\circ} \mathrm{C}\right)$ for at least $10 \mathrm{~min}$ to ensure complete phase separation, and then rinsed out with deionized and distilled water. For comparison, activated carbon modified with cellulose acetate only (CA) was prepared with the same method. All adsorbents were kept in deionized water and stored in a refrigerator at $4{ }^{\circ} \mathrm{C}$ until use.

\subsubsection{Adsorbate}

Dieldrin, which is defined as one of the initial 12 POPs, according to the Stockholm Convention on POPs [15], has been used extensively as an insecticide until 1970s, and can still be found in the different components of environment in many countries and areas at the present time [16,17]. In this study, dieldrin was chosen as a model chemical to represent toxic POPs. The molecular weight of dieldrin is 381 , the water solubility is $0.195 \mathrm{mg}^{-1}$ [18], and the octanol-water coefficient $\left(\log K_{\mathrm{ow}}\right)$ is in the range of 4.30-5.48 [19,20], indicating comparatively strong hydrophobicity.

Stock solution was prepared by dissolving appropriate quantities of pesticides-grade standard (99.0\% purity, Environmental Protection Center of Agricultural Department, Beijing, China) in $n$-hexane, which was refrigerated until use.

Dieldrin solution was prepared by directly adding the dieldrin stock solution to deionized and distilled water without the assistance of organic solvent. Solution was sealed in conical flasks and agitated mechanically for $24 \mathrm{~h}$ to obtain homogeneous aqueous solution.

\subsection{Methods}

\subsubsection{Adsorption equilibrium}

Preliminary kinetic tests were carried out in order to determine the equilibrium time. And it was assumed that equilibrium was attained when no further changes in dieldrin uptake were observed after $48 \mathrm{~h}$.

Adsorption isotherms were obtained by mixing $1 \mathrm{~g}$ adsorbent with $100 \mathrm{ml}$ dieldrin solution of different initial concentrations $\left(1,3,5,10,20\right.$ and $\left.50 \mu \mathrm{g} \mathrm{l}^{-1}\right)$. The suspensions were agitated by a mechanical shaker at 170 revolutions per minute (rpm). The temperature was controlled at $25^{\circ} \mathrm{C}$ by air bath. Samples for analysis were taken after $48 \mathrm{~h}$ contact time.

\subsubsection{Adsorption kinetics}

Batch adsorption experiments were used to investigate the effects of some major kinetic parameters, such as initial concentration, temperature, shaking speed and $\mathrm{pH}$, on the uptake kinetics of dieldrin on CA-T. Adsorption kinetic test was carried out in $500 \mathrm{ml}$ sealed conical flasks. A liquid volume of $250 \mathrm{ml}$ and an amount of $5 \mathrm{~g} \mathrm{CA}$-T were used for all tests. Samples were withdrawn at regular intervals to analyze.

2.2.2.1. Effects of different operating conditions. Initial concentration ranged between 10 and $30 \mu \mathrm{gl}^{-1}$, temperature ranged between 5 and $35^{\circ} \mathrm{C}$, and shaking speed ranged between 0 and $170 \mathrm{rpm}$. Using an Orion 720 APLUS Benchtop meter (Thermo Orion Co., USA), $\mathrm{pH}$ that ranged from 4 to 8 was adjusted with $0.1 \mathrm{M} \mathrm{HCl}$ or $0.1 \mathrm{M} \mathrm{NaOH}$.

2.2.2.2. Effects of the addition of humic acid (HA). Humic acid (HA, C.R.), purchased from Huabei Development Center for Special Chemical Reagents (Tianjin, China), was dissolved in deionized and distilled water to model NOMs. HA solution was filtered through a $0.45 \mu \mathrm{m}$ membrane before use. TOC, measured by Phoenix 8000 TOC Analyzer (Tekmar-Dohrmann Co., USA), served as the parameter for NOMs quantification.

The initial concentration of dieldrin solution was $20 \mu \mathrm{gl}^{-1}$. HA solution was added to obtain a TOC value of $3 \mathrm{mgl}^{-1}$. The 
suspension was shaken at $170 \mathrm{rpm}$. The initial $\mathrm{pH}$ of the solution was 7.0, and the temperature was kept at $25^{\circ} \mathrm{C}$. For comparison, adsorption tests of dieldrin on CA-T, CA and GAC were performed separately under the same operating condition.

\subsubsection{Analytical procedures}

Dieldrin presents in water samples at a trace level, whose analysis requires first an extraction and a concentration. In our experiment, liquid-liquid extraction (LLE) was used for the determination of residual concentrations of dieldrin in samples.

Each water sample $(5 \mathrm{ml})$ was enriched by LLE with $1 \mathrm{ml} n$ hexane (GC grade, Fisher Scientific Company, USA) for three times in a separating funnel. The extracts were evaporated under a gentle stream of nitrogen and concentrated to a volume of $0.5 \mathrm{ml}$. Anhydrous sodium sulfate of analytical grade (Beijing Chemical Reagent Co., Beijing, China) was added to remove any moisture, which was dried at $450{ }^{\circ} \mathrm{C}$ for $4 \mathrm{~h}$ before use.

The analysis of residual concentrations of dieldrin was performed on a Agilent $6890 \mathrm{~N}$ gas chromatograph (Agilent Technologies, USA), equipped with a split-splitless injector and a ${ }^{63} \mathrm{Ni} \mu$-electron capture detector. A HP-5 capillary column ( $30 \mathrm{~m} \times 0.32 \mathrm{~mm}$ i.d., film thickness of $0.17 \mu \mathrm{m}$ ) was purchased from J\&W Scientific (USA). Column temperature was programmed at $85^{\circ} \mathrm{C}$ initially, increased at $10^{\circ} \mathrm{C} \mathrm{min}{ }^{-1}$ to $180^{\circ} \mathrm{C}$, held for $15 \mathrm{~min}$, then ramped at $20^{\circ} \mathrm{C} \mathrm{min}^{-1}$ to $280^{\circ} \mathrm{C}$, and held for $30 \mathrm{~min}$. The injector temperature was set at $250^{\circ} \mathrm{C}$ and the detector at $300{ }^{\circ} \mathrm{C}$, respectively. Nitrogen gas of extra purity ( $>99.999 \%)$ was used as the carrier gas at a flow rate of $1 \mathrm{ml} \mathrm{min}^{-1}$ and a pressure of $16 \mathrm{psi}$. A sample volume of $1 \mu \mathrm{l}$ was injected in the splitless mode. Chromatograms were recorded and analyzed by the software of HP Chem-Station.

Glassware used throughout the experiment were cleaned by soaking overnight in a $10 \%(\mathrm{v} / \mathrm{v})$ nitric acid solution, rinsing with deionized and distilled water, and drying at $120^{\circ} \mathrm{C}$ for $2 \mathrm{~h}$. Analysis of three blanks ( $250 \mathrm{ml}$ deionized and distilled water) was subject to assess the interference from the regents and glassware. The blank runs revealed that no impurity influenced the analytical quality. GC analysis was repeated twice for each replicate sample. The recognition of dieldrin in the extracts was based on chromatographic retention time of standard samples by operating HP Chem-Station. The quantitative determination of dieldrin was achieved using the method of external standards and the calibration curves. Recovery of the targeted dieldrin was $87.5 \pm 10.5 \%$, which demonstrated that favorable recoveries and good repeatability were obtained in the process of the experiment.

\section{Results and discussion}

\subsection{Dieldrin adsorption isotherms}

The correlation of equilibrium data using either theoretical or empirical equation is essential for adsorption data interpretation and prediction. An important model widely used in removal of hydrophobic organic pollutants from water is the Freundlich isotherm representing a non-linear equilibrium between the phases (Eq. (1)):

$q_{\mathrm{eq}}=K_{\mathrm{F}} C_{\mathrm{eq}}^{1 / n}$

where $q_{\text {eq }}$ is the adsorption capacity of an adsorbent at equilibrium $\left(\mu \mathrm{g} \mathrm{g}^{-1}\right), C_{\mathrm{eq}}$ the equilibrium concentration of the adsorbate $\left(\mu \mathrm{g}^{-1}\right)$ and $K_{\mathrm{F}}$ is an indication of the adsorption capacity of the adsorbent, while the parameter $n$ indicates the effect of concentration on the adsorption capacity and represents the adsorption intensity.

The adsorption capacity of an adsorbent, $q_{\mathrm{eq}}$, is calculated by means of equilibrium studies. Eq. (2) establishes the mass balance of process at equilibrium condition:

$q_{\mathrm{eq}}=\frac{V\left(C_{0}-C_{\mathrm{eq}}\right)}{m}$

where $C_{0}$ is the initial concentration of the adsorbate $\left(\mu \mathrm{g} \mathrm{I}^{-1}\right)$, $m$ the adsorbent mass $(\mathrm{g})$ and $V$ is the solution volume (1).

The adsorption isotherms of dieldrin on CA-T, CA and GAC at $25^{\circ} \mathrm{C}$ were presented in Fig. 2. Results showed that CA-T presented a unique adsorption pattern and could remove dieldrin from aqueous solution effectively. The equilibrium adsorption capacity of the tested adsorbents followed the order: CA$\mathrm{T}>\mathrm{CA}>\mathrm{GAC}$. For example, at an initial dieldrin concentration of $10 \mu \mathrm{g}{ }^{-1}$, the equilibrium adsorption capacity of CA-T, CA and GAC was $1.94,1.88$ and $1.87 \mu \mathrm{g} \mathrm{g}^{-1}$, respectively. The difference between sorption amounts by three adsorbents seemed to be unconspicuous at the same initial dieldrin concentration, which was attributed to the narrow concentration range of dieldrin determined by its poor water solubility. However, it could be seen obviously in Fig. 2 that the difference of sorption amounts between CA-T and the other two adsorbents increased with the increase of equilibrium concentrations. CA-T appeared to be a promising adsorbent for removing dieldrin in trace amount from aqueous solution. Since CA-T had smaller specific surface area compared with the other two (specific surface areas of GAC, CA and CA-T are 797, 723 and $721 \mathrm{~m}^{2} \mathrm{~g}^{-1}$, respectively), its highest equilibrium adsorption capacity was attributed to the accumulation effect of triolein contained in CA-T on hydrophobic dieldrin. No maximum adsorption value was observed in the

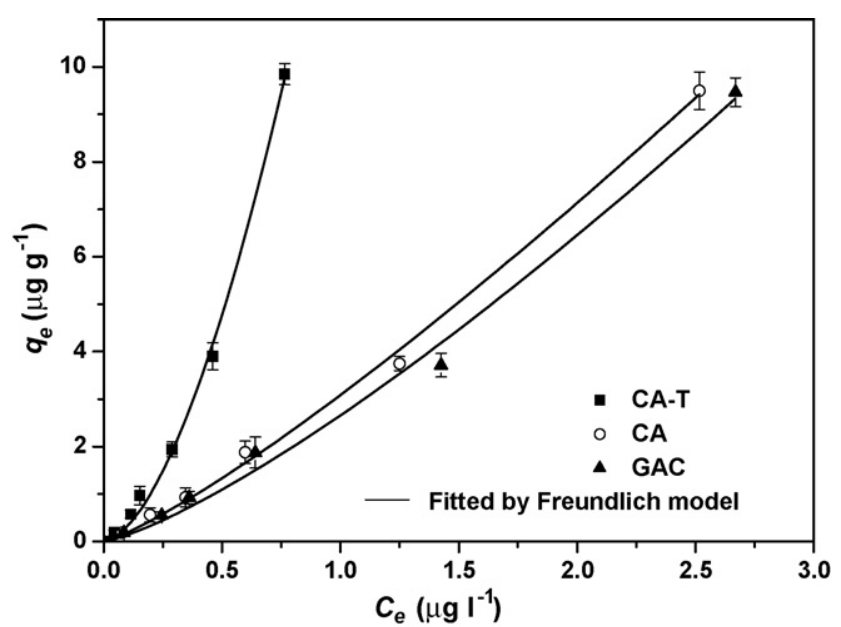

Fig. 1. Dieldrin adsorption isotherms at $25^{\circ} \mathrm{C}$. 
Table 1

Freundlich isotherm parameters of dieldrin adsorption

\begin{tabular}{lrll}
\hline Adsorbent & \multicolumn{1}{c}{$K_{\mathrm{F}}$} & $n$ & $R^{2}$ \\
\hline CA-T & 15.32 & 0.595 & 0.997 \\
CA & 3.08 & 0.827 & 0.998 \\
GAC & 2.66 & 0.781 & 0.994 \\
\hline
\end{tabular}

isotherm experiments as shown in Fig. 1, which could be due to the low concentration of dieldrin determined by its poor water solubility [18], and the immense adsorption capacity of CA-T.

The adsorption isotherms analysis of experimental data was based on Freundlich isotherms, and the corresponding Freundlich parameters along with correlation coefficients were given in Table 1. The results indicated that the experimental data fitted the Freundlich isotherm well in a range of initial concentrations from 1 to $50 \mu \mathrm{g} \mathrm{l}^{-1}$, and the correlation coefficients were between 0.994 and 0.998 . The magnitude of $K_{\mathrm{F}}$ and $n$ values showed the easiest uptake of dieldrin and the highest equilibrium adsorptive capacity of CA-T.

Two isotherms, Langmuir and Linear isotherms had been additionally regressed with the experimental data to compare their applicability with Freundlich equation. Data analysis indicated that neither linear nor Langmuir isotherms reproduced equilibrium data of CA-T ideally. When experimental data were fitted with linear isotherms, the correlation coefficients of CA-
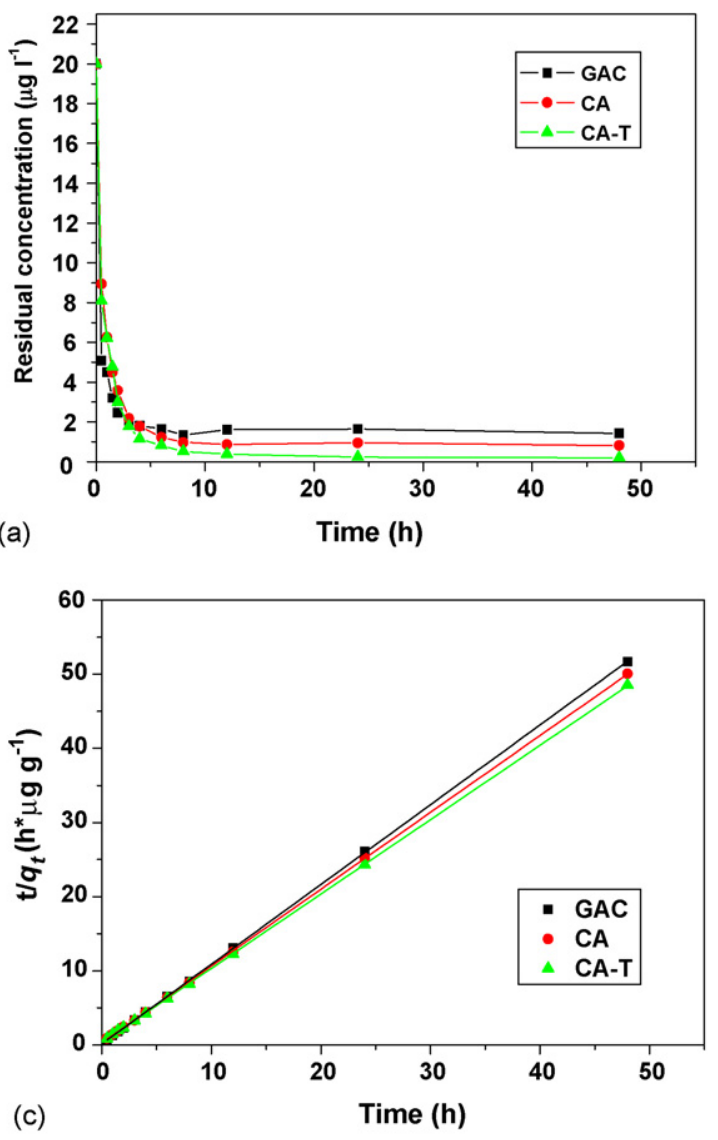

T, CA and GAC were 0.919, 0.986 and 0.976, respectively. The derivation linearity of the equilibrium data of CA-T showed that dieldrin was not adsorbed onto CA-T by simplex partition mechanism. For Langmuir adsorption isotherm, the regression coefficient values were all lower than 0.5 . These results indicated that the adsorption of dieldrin did not follow the Langmuir adsorption isotherm, which might be attributed to the energetic heterogeneity of the adsorbents, since Langmuir isotherm model assumes uniform energies of adsorption onto the surface and no transmigration of adsorbate in the plane of the surface.

\subsection{Kinetics of dieldrin removal}

The kinetics of sorption that describes the solute uptake rate governing the residence time of the sorption reaction is one of the important characteristics that define the efficiency of sorption. Hence, in the present study, the kinetics of dieldrin adsorption on three adsorbents was investigated in detail. The effects of adding HA to the adsorption systems and changing operation conditions were also discussed.

\subsubsection{Comparison of adsorbents}

Fig. 2(a) shows the adsorption data of dieldrin by three adsorbents at different time intervals. The adsorption of dieldrin onto three adsorbents was found to be time dependent. The adsorption reaction was rapid in the first $3 \mathrm{~h}$, when the residual
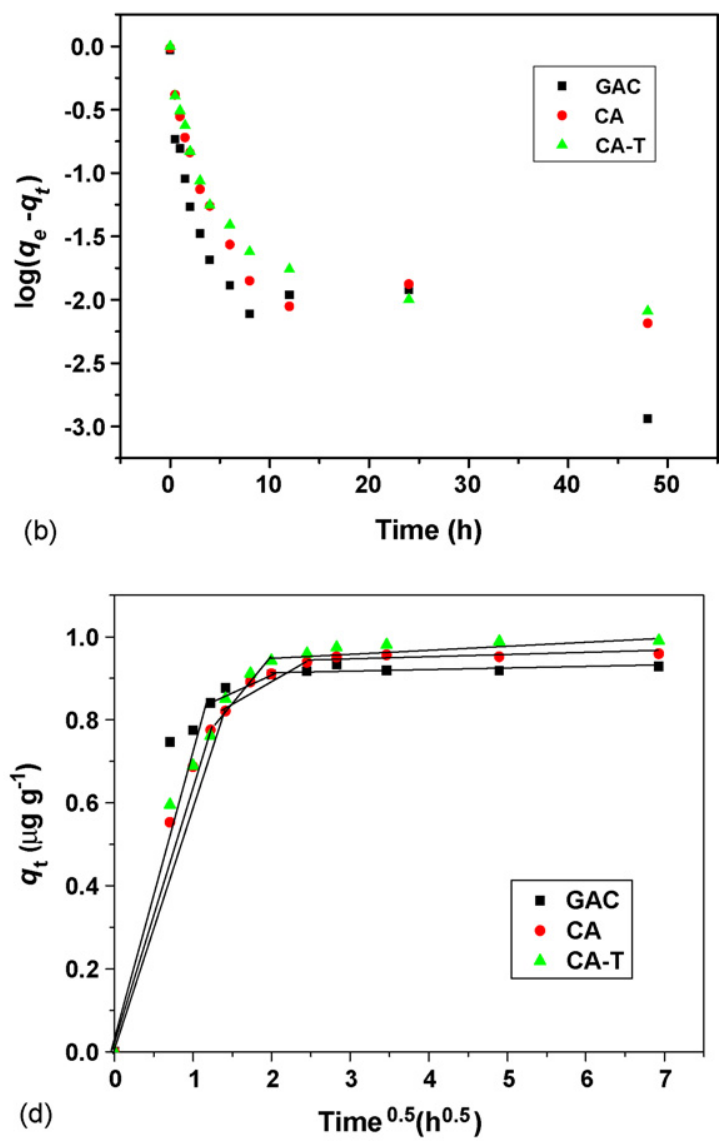

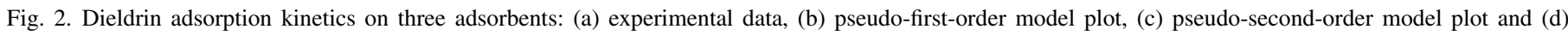
intra-particle diffusion model plot. 
Table 2

Kinetic parameters and correlation coefficients of dieldrin adsorption

\begin{tabular}{|c|c|c|c|c|c|c|c|c|c|c|}
\hline & \multicolumn{2}{|c|}{ Pseudo-first-order } & \multicolumn{4}{|c|}{ Pseudo-second-order } & \multicolumn{4}{|c|}{ Intraparticle diffusion } \\
\hline & $k_{1}\left(\mathrm{~h}^{-1}\right)$ & $R^{2}$ & $\begin{array}{l}V_{0} \\
\left(\mu g g^{-1} h^{-1}\right)\end{array}$ & $\begin{array}{l}q_{\mathrm{eq}}(\mu \mathrm{g} \\
\left.\mathrm{g}^{-1}\right)\end{array}$ & $\begin{array}{l}k_{2} \\
\left(\mu g^{-1} \mathrm{gh}^{-1}\right)\end{array}$ & $R^{2}$ & $\begin{array}{l}k_{i, 1} \\
\left(\mu \mathrm{gg}^{-1} \mathrm{~h}^{-0.5}\right)\end{array}$ & $\begin{array}{l}k_{i, 2} \\
\left(\mu \mathrm{gg}^{-1} \mathrm{~h}^{-0.5}\right)\end{array}$ & $\begin{array}{l}k_{i, 3} \\
\left(\mu \mathrm{gg}^{-1} \mathrm{~h}^{-0.5}\right)\end{array}$ & $R^{2}$ \\
\hline CA-T & 0.0359 & 0.594 & 3.44 & 0.998 & 3.46 & 0.99997 & 0.681 & 0.223 & 0.00815 & 0.951 \\
\hline $\mathrm{CA}$ & 0.0371 & 0.514 & 3.47 & 0.965 & 3.73 & 0.99995 & 0.637 & 0.108 & 0.00303 & 0.956 \\
\hline GAC & 0.0434 & 0.600 & 7.35 & 0.930 & 8.50 & 0.99997 & 0.777 & 0.0843 & 0.00218 & 0.891 \\
\hline $\mathrm{CA}-\mathrm{T}+\mathrm{HA}$ & 0.0353 & 0.684 & 3.19 & 0.960 & 3.46 & 0.99998 & 0.608 & 0.205 & 0.00778 & 0.930 \\
\hline $\mathrm{CA}+\mathrm{HA}$ & 0.0351 & 0.559 & 2.70 & 0.951 & 5.19 & 0.99995 & 0.591 & 0.0840 & 0.00278 & 0.901 \\
\hline $\mathrm{GAC}+\mathrm{HA}$ & 0.0329 & 0.529 & 2.28 & 0.775 & 3.79 & 1 & 0.673 & 0.00658 & 0.000361 & 0.888 \\
\hline
\end{tabular}

concentrations reached $1.81,1.79$ and $1.15 \mu \mathrm{gl}^{-1}$ for GAC, $\mathrm{CA}$, and CA-T, respectively. GAC had the fastest adsorption rate during that period, which might be due to its larger specific surface area and fresh porous surface that made the adsorption much easier. As time went by, the adsorption rates in all three systems slowed down gradually. CA-T presented higher adsorption capacity and removal efficiency than GAC in the rest of time, which was assumed due to the selective accumulation property of triolein towards hydrophobic dieldrin. At the end of adsorption for $48 \mathrm{~h}$, residual concentrations of dieldrin were $1.42,0.82$ and $0.20 \mu \mathrm{gl}^{-1}$ in the reaction systems of GAC, CA and CA-T, respectively. The kinetic result, indicating a higher removal percentage of dieldrin by CA-T than that of GAC, was consistent with the adsorption isotherm test.

Three kinetics models were used, including pseudo-firstorder model, pseudo-second-order model and intraparticle diffusion model, in order to investigate the adsorption behavior of three adsorbents and the effects of adding HA to the adsorption systems.

The kinetic rate equation of pseudo-first-order adsorption is expressed as [20]:

$\frac{\mathrm{d} q_{t}}{\mathrm{~d} t}=k_{1}\left(q_{\mathrm{eq}}-q_{t}\right)$

The integrated pseudo-first-order rate equation is written as

$\log \left(q_{\mathrm{eq}}-q_{t}\right)=\log q_{\mathrm{eq}}-k_{1} t$

where $q_{\mathrm{eq}}$ and $q_{t}$ are the amounts of adsorbed dieldrin at equilibrium and any time $t$ ( $\mu \mathrm{gg}^{-1}$ adsorbent), respectively, $k_{1}\left(\mathrm{~h}^{-1}\right)$ is the equilibrium rate constant of the first-order sorption, and $t$ is the adsorption time (h). $k_{1}$ can be calculated according to the linear plot of $\log \left(q_{\mathrm{eq}}-q_{t}\right)$ versus $t$. A larger adsorption rate constant $k_{1}$ usually represents a quicker adsorption rate.

The pseudo-second-order kinetic model can be solved with the following equations [21,22]. The kinetic rate equation is expressed as

$\frac{\mathrm{d} q_{t}}{\mathrm{~d} t}=k_{2}\left(q_{\mathrm{eq}}-q_{t}\right)^{2}$

where $k_{2}\left(\mu \mathrm{g}^{-1} \mathrm{~g} \mathrm{~h}^{-1}\right)$ represents the pseudo-second-order rate constant for the kinetic model. By integrating Eq. (5) with the boundary conditions of $q_{t}=0$ at $t=0$ and $q_{t}=q_{t}$ at $t=t$, the following linear equation can be obtained:

$\frac{1}{q_{\mathrm{eq}}-q_{t}}=\frac{1}{q_{\mathrm{eq}}}+k_{2} t$

$\frac{t}{q_{t}}=\frac{1}{V_{0}}+\frac{1}{q_{\mathrm{eq}}} t$

$V_{0}=k_{2} q_{\mathrm{eq}}^{2}$

where $V_{0}\left(\mu \mathrm{gg}^{-1} \mathrm{~h}^{-1}\right)$ is the initial sorption rate. Therefore, the $V_{0}$ and $q_{\text {eq }}$ values of kinetic tests can be determined experimentally by plotting $t / q_{t}$ versus $t . k_{2}$ can be determined by plotting $t / q_{t}$ versus $t$ based on Eq. (7).

The most widely applied intraparticle diffusion model for bio-sorption systems is given by Weber and Morris as [23]:

$q_{t}=k_{i} t^{0.5}$

where $q_{t}$ is the amount of adsorbate at time $t\left(\mu \mathrm{gg}^{-1}\right)$ and $k_{i}$ is the rate constant $\left(\mu \mathrm{g} \mathrm{g}^{-1} \mathrm{~h}^{-0.5}\right)$.

Table 2 and Fig. 2(b)-(d) present the results of fitting experimental data with pseudo-first-order, pseudo-second-order and intraparticle diffusion models, respectively. The adsorption of dieldrin onto three adsorbents did not follow the pseudo-firstorder equation, as shown in Fig. 2(b) and Table 2. The correlation coefficients were between 0.514 and 0.600. And Fig. 2(c) and Table 2 indicated that the pseudo-second-order model provided the best correlation of the adsorption kinetics data. The correlation coefficients were above 0.999. Among three adsorbents used in this study, GAC had the fastest initial adsorption rate of $7.35 \mu \mathrm{g} \mathrm{g}^{-1} \mathrm{~h}^{-1}$, and CA-T enjoyed the highest equilibrium adsorption capacity of $0.998 \mu \mathrm{g} \mathrm{g}^{-1}$. Fig. 2(d) was the plot of $q_{\mathrm{t}}$ versus $t^{0.5}$ according to the intraparticle diffusion model, which presented the character of multi-linearity and indicated that two or more steps occurred in the adsorption processes [24]. The first sharper portion was the external surface adsorption or instantaneous adsorption stage. The second portion was the gradual adsorption stage, where the intraparticle diffusion was rate-controlled. The third portion was the final equilibrium stage, where the intraparticle diffusion started to slow down due to the extremely low solute concentration in solution. The intraparticle diffusion constants could be calculated using Eq. (7). 
Intraparticle diffusion constants of different stages $\left(k_{i, 1}, k_{i, 2}\right.$ and $\left.k_{i, 3}\right)$ expressed the diffusion rates of each stage in the adsorption process. Results listed in Table 2 indicated that the order of absorption rate was the first stage $\left(k_{i, 1}\right)>$ the second stage $\left(k_{i, 2}\right)>$ the third stage $\left(k_{i, 3}\right)$ for all adsorbents. At the beginning stage, dieldrin was adsorbed by the exterior surface of adsorbents, and the adsorption rates were very fast. The fastest adsorption rate of GAC was assumed due to its large specific surface area. When the adsorption of the exterior surface reached saturation, the molecular dieldrin further entered the particle and was adsorbed by the interior surface of the particle. When the molecular dieldrin diffused in the pore of the particle, the diffusion resistance increased, which caused the diffusion rate to decrease. With decrease of the dieldrin concentration in the solution, the diffusion rate became lower and lower, the diffusion processes reached the final equilibrium stage. Therefore the changes of $k_{i, 1}, k_{i, 2}$ and $k_{i, 3}$ could be attributed to the adsorption stages of the exterior surface, interior surface and equilibrium, respectively. However, both $k_{i, 2}$ and $k_{i, 3}$ of CA-T were much higher than that of GAC, indicating that the adsorption rates of dieldrin on CA-T decreased much slower than GAC. It was estimated due to the special triolein-embedded structure of CAT. Since triolein had strong accumulating effect to hydrophobic dieldrin, it might increase the equilibrium adsorption capacity and enhance the removal efficiency of CA-T. The correlation coefficients between 0.888 and 0.956 illustrate that experimental data can also be reasonably described by the intraparticle diffusion model.

\subsubsection{Effects of $H A$ on dieldrin adsorption}

Organic contamination is a particular problem in the process of water supply. The adsorption capacity and adsorption rate are lower in natural water than in a single-solute adsorption system in pure water, because activated carbon usually removes not only the target contaminant but also natural organic matters (NOMs) [25]. Using HA to simulate NOMs, experiments were carried out to investigate the effects of NOMs on dieldrin removal by three adsorbents used in our study.

Fig. 3 shows the experimental data of effects of HA on dieldrin adsorption. It could be seen that dieldrin adsorption was significantly affected in GAC system with HA, with a residual concentration of $3.846 \mu \mathrm{gl}^{-1}$, while in the other two reaction systems with HA, the addition of HA had little effect on the uptake of dieldrin. The TOC of solution in GAC system reduced from the initial $3 \mathrm{mg} \mathrm{l}^{-1}$ to the final $1.296 \mathrm{mg} \mathrm{l}^{-1}$, whereas that of solutions in CA-T and CA systems remained almost unchanged. On the whole, CA-T presented a good selectivity to hydrophobic dieldrin, but GAC showed a poor one. The $\mathrm{pH}$ of solution was measured in all experiments, and results indicated that it remained almost unchanged at $\mathrm{pH} 6.8$ after adding HA to adsorption systems. Consequently, the effects of $\mathrm{pH}$ on the adsorption process could be neglected.

From the pseudo-second-order kinetic model analytical results shown in Table 2, it could be easily found that the initial adsorption rate reduced from 7.35 to $2.28 \mu \mathrm{g} \mathrm{g}^{-1} \mathrm{~h}^{-1}$, and the adsorption capacity at equilibrium decreased from 0.930 to $0.775 \mu \mathrm{g} \mathrm{g}^{-1}$ after adding the HA to GAC system, which indi-

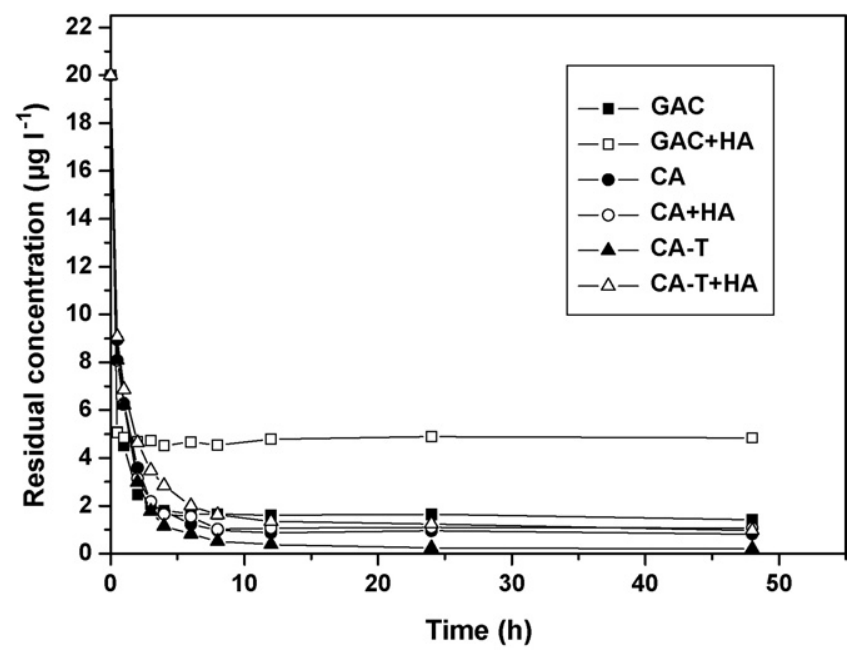

Fig. 3. Effects of HA on dieldrin removal.

cated that the adsorption of dieldrin on GAC was affected by the presence of HA obviously. While the values of the initial adsorption rate and the adsorption capacity at equilibrium of dieldrin adsorbed by CA and CA-T only reduced slightly when HA appeared in the reaction systems. Results of the intraparticle diffusion model also proved that the adsorption rates of dieldrin on GAC were slowed down obviously, especially in the last two stages, and that of CA and CA-T was only decreased in some sort.

\subsubsection{Effects of some key factors on dieldrin adsorption by $C A-T$}

Fig. 4 shows the effects of the initial concentration, temperature, shaking speed and $\mathrm{pH}$ on adsorption behavior of dieldrin on CA-T, which indicated that adsorption reaction was very rapid at the beginning stage, then slowed down gradually. Fig. 4(a) proved that the adsorption rate increased with the increase of the initial concentration, which was probably the result of increase of driving force (DF). The DF of diffusion was very important for adsorption processes and DF changed with solute concentration in bulk solution generally. The increases of dieldrin concentration resulted in the increase of DF, which would increase the diffusion rate of the molecular dieldrin in particles. While at the end of $48 \mathrm{~h}$ adsorption, residual concentrations of dieldrin in three solutions with different initial concentrations almost reached the same level. Comparing the experimental results obtained from Fig. 4(b), it could be found that the adsorption of dieldrin onto CA-T speeded up with the increase in temperature, which indicated that this adsorption reaction was endothermic. Fig. 4(c) presented the adsorption of dieldrin onto CA-T under shaking conditions of 0,80 and $170 \mathrm{rpm}$. It could be seen that dieldrin adsorption was fast under shaking conditions, and the equilibrium was reached within $12 \mathrm{~h}$ at $170 \mathrm{rpm}$. While under the static condition, the adsorption of dieldrin onto CA-T was a very slow procedure. Within the first $1 \mathrm{~h}$, only about $25 \%$ of dieldrin was adsorbed onto CA-T. In the adsorption process, dieldrin was firstly transferred to solid surfaces from bulk solutions and then adsorbed at active sites, which was slow and was a rate 



Fig. 4. Effects of experimental conditions on the adsorption of dieldrin on CA-T: (a) initial concentration, (b) temperature, (c) shaking speed and (d) pH.

determining step. When the mixture was shaken with certain rotation speed, the solid particles of adsorbent moved around rapidly in the solutions, and the concentration of dieldrin near adsorbent surface could be very close to the bulk concentration. The external mass transfer of dieldrin was speeded up, and the time consumed to reach equilibrium was shortened. Shaking increased the diffusion in the boundary layer and consequently the adsorption rate. Fig. 4(d) indicated that $\mathrm{pH}$ had little effects on the adsorption of dieldrin onto CA-T.

In summary, the adsorption rate of dieldrin on CA-T increased with initial concentration, temperature and shaking speed and there was no significant change in the removal rate of dieldrin in the $\mathrm{pH}$ range of $4-8$.

\subsection{Thermodynamic analysis of dieldrin adsorption on $C A-T$}

The thermodynamic analysis of dieldrin adsorption on CA-T with experimental data of different temperatures was conducted. Thermodynamic parameters, such as change in free energy $\left(\Delta G^{\circ}\right)$, enthalpy $\left(\Delta H^{\circ}\right)$ and entropy $\left(\Delta S^{\circ}\right)$, were calculated from the variation of the thermodynamic equilibrium constant $K_{0}$ with the change in temperature. The calculation methods employed are discussed in detail by Niwas et al. [26]. $K_{0}$ for the adsorption reaction can be defined as follows:

$K_{0}=\frac{\alpha_{\mathrm{s}}}{\alpha_{\mathrm{e}}}=\frac{v_{\mathrm{s}}}{v_{\mathrm{e}}} \frac{C_{\mathrm{s}}}{C_{\mathrm{e}}}$ where $\alpha_{\mathrm{s}}$ is the activity of adsorbed solute, $\alpha_{\mathrm{e}}$ is the activity of the solute in solution at equilibrium, $C_{\mathrm{s}}$ is the surface concentration of dieldrin in millimoles per gram of CA-T, $C_{\mathrm{e}}$ is the concentration of dieldrin at equilibrium $\left(\mathrm{mmol} \mathrm{ml}^{-1}\right), v_{\mathrm{s}}$ is the activity coefficient of the adsorbed solute and $v_{\mathrm{e}}$ is the activity coefficient of the solute in solution. As the concentration of the solute in the solution approaches zero, the activity coefficient approaches unity, reducing Eq. (10) to the following form:

$K_{0}=\frac{\alpha_{\mathrm{s}}}{\alpha_{\mathrm{e}}}=\frac{C_{\mathrm{s}}}{C_{\mathrm{e}}}$

Values of $K_{0}$ are obtained by plotting $\ln \left(C_{\mathrm{s}} / C_{\mathrm{e}}\right)$ versus $C_{\mathrm{s}}$ and extrapolating $C_{\mathrm{s}}$ to zero. The straight line obtained is fitted to the points based on a least-squares analysis. Its intercept with the vertical axis gives the values of $K_{0}$. Standard free energy changes $\left(\Delta G^{\circ}, \mathrm{kJ} \mathrm{mol}^{-1}\right)$ for interactions are calculated from the relationship:

$\Delta G^{\circ}=-R T \ln K_{0}$

where $R$ is the universal gas constant, $8.314 \mathrm{~J} \mathrm{~mol}^{-1} \mathrm{~K}^{-1}$, and $T$ is the temperature in Kelvin. The average standard enthalpy change $\left(\Delta H^{\circ}, \mathrm{kJ} \mathrm{mol}^{-1}\right)$ is then calculated from the Van't Hoff equation:

$\ln K_{0}\left(T_{3}\right)-\ln K_{0}\left(T_{1}\right)=\frac{-\Delta H^{\circ}\left(T_{1}-T_{3}\right)}{R}\left(\frac{1}{T_{3}}-\frac{1}{T_{1}}\right)$

where $T_{3}$ and $T_{1}$ are two different temperatures. 
Table 3

Thermodynamic parameters of dieldrin adsorption on CA-T

\begin{tabular}{lllll}
\hline$T(\mathrm{~K})$ & $K_{0}$ & $\Delta G^{\circ}\left(\mathrm{kJ} \mathrm{mol}^{-1}\right)$ & $\Delta H^{\circ}\left(\mathrm{kJ} \mathrm{mol}^{-1}\right)$ & $\Delta S^{\circ}\left(\mathrm{kJ} \mathrm{mol}^{-1} \mathrm{~K}^{-1}\right)$ \\
\hline 288.15 & 2.52 & -18.76 & & 0.082 \\
298.15 & 4.81 & -21.02 & 33.82 & 0.071 \\
308.15 & 6.30 & -22.41 & & 0.073 \\
\hline
\end{tabular}

Standard entropy changes $\left(\Delta S^{\circ}, \mathrm{kJ} \mathrm{mol}^{-1} \mathrm{~K}^{-1}\right)$ are calculated using the equation:

$\Delta G^{\circ}=\Delta H^{\circ}-T \Delta S^{\circ}$

The values obtained were given in Table 3. A positive value of the standard enthalpy change $\left(\Delta H^{\circ}\right)$ indicated that the adsorption of dieldrin on CA-T was endothermic. It was supported by the increasing adsorption of dieldrin with the increase in temperature. Since the free energy changes $\left(\Delta G^{\circ}\right)$ were negative and were accompanied by positive entropy changes $\left(\Delta S^{\circ}\right)$, the reactions were spontaneous with high affinity for dieldrin [25]. The negative $\Delta G^{\circ}$ value increased with an increase in temperature, indicating that the spontaneous nature of adsorption is proportional to the temperature.

\section{Conclusions}

A novel composite adsorbent containing triolein was developed, which was found to be effective for the removal of hydrophobic dieldrin from aqueous solutions. The adsorption isotherm data of dieldrin fitted Freundlich equation well, and the adsorption capacity and removal efficiency of CA-T was higher than that of CA and GAC. The adsorption data was well described by both pseudo-second-order kinetics and intraparticle diffusion models. The addition of HA hindered the uptake of dieldrin by GAC obviously, but had little effect on dieldrin adsorption by CA-T, which proved that CA-T had an excellent selectivity to hydrophobic dieldrin. The adsorption rate of dieldrin on CA-T increased with the increase of shaking speed, initial concentration and temperature, and was $\mathrm{pH}$ independent in the $\mathrm{pH}$ range $4-8$. The adsorption reaction was spontaneous with a high affinity and the adsorption of dieldrin on CA-T was an endothermic reaction, indicated by the negative free energy changes accompanied by a positive entropy changes.

\section{Acknowledgements}

The authors gratefully acknowledge the generous financial support of this work by National Natural Science Foundation of China $(50578154,20337020)$ and Hi-Tech Research and Development Program of China (2005AA642020). The authors are indebted to two anonymous reviewers for providing constructive comments on previous review of this manuscript.

\section{References}

[1] R.J. Norstrom, M. Simon, C.G. Derek, R.E. Schweinsburg, Organochlorine contaminants in arctic marine food chains: identification, geographical distribution, and temporal trends in polar bears, Environ. Sci. Technol. 22 (1988) 1063-1071.

[2] H. Iwata, S. Tanabe, N. Sakai, A. Nishimura, R. Tatsukawa, Distribution of persistent organochlorines in the oceanic air and surface sea water and the role of ocean on their global transport and fate, Environ. Pollut. 85 (1994) $15-33$.

[3] K.S. Guruge, S. Tanabe, Contamination by persistent organochlorines and butyltin compounds in the west coast of Sri Lanka, Mar. Pollut. Bull. 42 (2001) 179-186.

[4] T. Colborn, M.J. Smolen, Epidemiological analysis of persistent organochlorine contaminations in cetaceans, Rev. Environ. Contam. T. 146 (1996) 91-172.

[5] K.C. Jones, P.D. Voogt, Persistent organic pollutants (POPs): state of the science, Environ. Pollut. 100 (1999) 209-221.

[6] K. Vasanth Kumar, S. Sivanesan, Isotherm parameters for basic dyes onto activated carbon: comparison of linear and non-linear method, J. Hazard. Mater. B129 (2006) 147-150.

[7] T. Karanfil, J.E. Kilduff, M.A. Schlautman, W.J. Weber, Adsorption of organic macromolecules by granular activated carbon. 1. Influence of molecular properties under anoxic solution conditions, Environ. Sci. Technol. 30 (1996) 2187-2194.

[8] B. Özkaya, Adsorption and desorption of phenol on activated carbon and a comparison of isotherm models, J. Hazard. Mater. B129 (2006) 158-163.

[9] A.T. Fisk, G.A. Stern, K.A. Hobson, W.J. Strachan, M.D. Loewen, R.J. Norstrom, Persistent organic pollutants (POPs) in a small, herbivorous, arctic marine zooplankton (Calanus hyperboreus): trends from April to July and the influence of lipids and trophic transfer, Mar. Pollut. Bull. 43 (2001) 93-101.

[10] Y.B. Lu, Z.J. Wang, J.N. Huckins, Review of the background and application of triolein-containing semipermeable membrane devices in aquatic environmental study, Aquat. Toxicol. 60 (2002) 139-153.

[11] J.D. Petty, C.E. Orazio, J.N. Huckins, R.W. Gale, J.A. Lebo, J.C. Meadows, K.R. Echols, W.L. Cranor, Considerations involved with the use of semipermeable membrane devices for monitoring environmental contaminants, $\mathrm{J}$. Chromatogr. A 879 (2000) 83-95.

[12] A.M. Lazarin, C.A. Borgo, Y. Gushikem, A platinum electrode coated with a copper (II) aminopropyl complex-cellulose acetate membrane and its use for dissolved oxygen reduction, J. Membr. Sci. 221 (2003) 175-184.

[13] J.H. Qu, J. Ru, H.J. Liu, R.H. Dai, Preparation method of a trolein-activated carbon composite adsorbent for efficiently removing POPs from water. Chinese Patent (2004), Application No: 2004100622631.

[14] J. Ru, H.J. Liu, J.H. Qu, A.M. Wang, R.H. Dai, Characterization and adsorption behavior of a novel triolein-embedded activated carbon composite adsorbent, Chin. Sci. Bull. 50 (2005) 2788-2790.

[15] UN, Stockholm Convention on Persistent Organic Pollutants. United Nations, 2001, http://www.pops.int.

[16] R.A. Doong, Y.C. Sun, P.L. Liao, C.K. Peng, S.C. Wu, Distribution and fate of organochlorine pesticide residues in sediments from the selected rivers in Taiwan, Chemosphere 48 (2002) 237-246.

[17] Z.L. Zhang, H.S. Hong, J.L. Zhou, J. Huang, G. Yu, Fate and assessment of persistent organic pollutants in water and sediment from Minjiang River Estuary, Southeast China, Chemosphere 52 (2003) 14231430.

[18] X.C. Jin, Pollution Chemistry of Organic Compounds-Toxic Organic Pollutants, Tsinghua University Press, Beijing, 1990, pp. 40 and 195 (in Chinese).

[19] D. Mackay, Correlation of bioconcentration factors, Environ. Sci. Technol. 16 (1982) 274-278.

[20] Y.B. Lu, Z.J. Wang, Accumulation of organochlorinated pesticides by triolein-containing semipermeable membrane device (triolein-SPMD) and rainbow trout, Water Res. 37 (2003) 2419-2425.

[21] X. Fan, D.J. Parker, M.D. Smith, Adsorption kinetics of fluoride on low cost materials, Water Res. 37 (2003) 4929-4937.

[22] X.J. Guo, F.H. Chen, Removal of arsenic by bead cellulose loaded with iron oxyhydroxide from groundwater, Environ. Sci. Technol. 39 (2005) 6808-6818.

[23] W.J. Weber, J.C. Morris, Kinetics of absorption on carbon from solution, J. Sanit. Eng. Div. Am. Soc. Civ. Eng. 89 (1963) 31-60. 
[24] F.C. Wu, R.L. Tseng, R.S. Juang, Kinetic modelling of liquid-phase absorption of reactive dyes and metal ions on chitosan, Water Res. 35 (2001) 613-618.

[25] Y. Matsui, Y. Fukuda, T. Inoue, T. Matsushita, Effect of natural organic matter on powdered activated carbon adsorption of trace contaminants: characteristics and mechanism of competitive adsorption, Water Res. 37 (2003) 4413-4424.

[26] R. Niwas, U. Gupta, A.A. Khan, K.G. Varshney, The adsorption of phosphamidon on the surface of styrene supported zirconium (IV) tungstophosphate: a thermodynamic study, Colloids Surf. A 164 (2000) 115-119. 